ARTICLE

https://doi.org/10.1057/s41599-019-0247-4

\title{
Two sides of the same coin? An investigation of the effects of frames on tax compliance and charitable giving
}

Cinzia Castiglioni (iD ${ }^{1}$, Edoardo Lozza ${ }^{1}$, Eric van Dijk ${ }^{2}$ \& Wilco W. van Dijk ${ }^{2}$

\begin{abstract}
Despite tax compliance being mandatory and charitable giving being voluntary, both can be seen as two sides of the same coin. Paying taxes and making monetary donations are two complementary ways to financially provide for the common good. Using goal-framing theory, an experimental study with a mixed-factorial design $(N=435)$ was conducted to test the effects of different frames on the intention to pay taxes and make charitable donations. Our results showed that for real taxpayers (i.e., for employees, self-employed, and entrepreneurs, but not for students) using a gain goal frame as a support to the normative goal frame was only effective in increasing intended tax compliance, whereas a supporting hedonic goal frame was only effective in increasing donation intention. In addition, it was found that gain and hedonic goal frames worked differently according to the prevailing motivation behind tax compliance and charitable giving. When the intrinsic motivation was already high, frames were ineffective (in the tax context) or even counter-productive (in the charitable giving context). In the presence of extrinsic motivations, instead, frames are especially effective.
\end{abstract}

\footnotetext{
${ }^{1}$ Department of Psychology, Università Cattolica del Sacro Cuore, Milan, Italy. ${ }^{2}$ Department of Social and Organisational Psychology, Leiden University, Leiden, The Netherlands. Correspondence and requests for materials should be addressed to C.C. (email: cinzia.castiglioni@unicatt.it)
} 


\section{Introduction}

ffective provision of services and public utilities is a key element of quality of life for most societies. Such provision can result from both paying taxes and making charitable donations, which are two mechanisms that can benefit society and enhance the overall welfare. Hence, most governments and institutions need to find a way to overcome the free-riding problem inherent in the financial provision of common goods and promote both tax compliance and charitable giving.

The economic literature seems to agree that taxes and donations are two different ways - one 'public', the other 'private' - of creating public value and increase the overall social welfare (Slavov, 2014; Sugden, 1984). Most countries depend on tax compliance to provide essential services, such as healthcare, education, and safety; whereas charitable giving plays a significant role in alleviating problems related to the crisis of the welfare state (Selle, 1993). Arguably, societies in which people do engage in these behaviours are better off than those in which people do not. Hence, any free-riding behaviour is a significant concern, as it means that governments, institutions, and NGOs are denied the revenues needed to provide services that are essential for ensuring the safety, health, and wellbeing of all citizens. The conjoint study of tax compliance and charitable giving may seem paradoxical, given their different nature. However, despite their intrinsic difference of being mandatory (tax compliance) or voluntary (charitable giving), they belong together, as any imperfectly enforced tax system involves an element of voluntary giving (Dwenger et al., 2016). This complementarity is in regard to the societal impact of tax payments and donations, and does not necessarily reflect how individuals view these mechanisms (i.e., at psychological level).

From a psychological perspective, there is a dearth of studies investigating if tax compliance and charitable giving are perceived as complementary forms of financial provision for the common good. Although both situations can be described as social dilemmas, as they involve a tension between what is best for the individual and what is best for the society as a whole (Dawes, 1980), no evidence in psychological literature can be found regarding the psychological equivalence from a layperson's perspective between paying taxes and making donations. An exception is a qualitative study (Castiglioni et al., 2018) which investigated lay people representations on the common good and its financial provision. It is suggested that, at least at formal and cognitive level, both paying taxing and making donations are perceived as indirect monetary ways to provide for the common good (the former as part of people's civic duty, the latter as a possible form of offering beneficence besides volunteering) whose effectiveness is subsidiary to the management and use of a third party (e.g., governments, NGOs, etc.). At affective level, instead, they are very different. When paying taxes, people are concerned mostly about the effects their contribution may have, and expect a material gain in return (i.e., public services); whereas when making a monetary donation, people are concerned mostly about the motivations behind the gesture, and expect an emotional gain in return (i.e., personal fulfilment and gratification). In other words, it seems that people might pursue different goals when involved in these two different forms of financial provision for the common good. Accordingly, a campaign aimed at promoting tax compliance should focus on the material outcomes citizens may obtain in return (e.g., public services). A campaign aimed at promoting charitable giving, instead, should focus on personal outcomes like fulfilment and gratification (e.g., 'warm glow' feelings), rather than on the material outcomes.

The above-mentioned study, however, has some limitations, as it is a preliminary exploration on the subject aimed at developing some insights rather than testing a-priori hypotheses. Thus, since the use of multiple methods to test a theory is crucial for a deeper understanding, we performed an experimental study aimed at testing whether using different goal frames increases the intention to financially provide for the common good. To test this, we refer to the goal-framing approach (Lindenberg and Steg, 2007), according to which a message is more likely to be effective if it corresponds to the recipients' goals. If the complementarity of tax payments and charitable giving in regard to their societal impact is also perceived at psychological level and people pursue the same goal when giving their contribution, we should expect different specific frames to be equally effective in both domains. If, however, people pursue different goals when paying taxes or when making donations, we should expect frames to differ in effectiveness. To the best of our knowledge, this is the first attempt in the psychological literature to compare the effectiveness of different frames on both paying taxes and making donations. Such comparison could help to shed some light on and develop new insights in both tax compliance and charitable giving research.

Next section will present rationale and hypotheses of the study, with a focus on the framing effects literature. Next, methodological details will be provided, including design, participants, procedure, and measures. Finally, the main results will be reported and discussed.

\section{Rationale and hypotheses}

Framing effects. Inspired by the seminal works of Kahneman and Tversky and the development of the Prospect Theory (1979), scholars have learned that frames matter since they affect the ways in which people understand problems and plan to solve them. Frames are powerful nudges (Sunstein and Thaler, 2009), and decision-making research has shown that different framing of information can alter people's decisions by changing their attitudes, emotions, or behaviour. Different framing classifications have been proposed (for a review, see Levin et al. 1998), such as 'risky choice framing' (Tversky and Kahneman, 1981) 'label framing' (Elliott et al. 1998), and 'valence framing' (Wheatley and Oshikawa, 1970).

The present study will refer to the 'goal-framing' theory (Lindenberg and Steg, 2007). The central idea is that goalswhich combine both cognitive and motivational elementsgovern or 'frame' what people attend to, what knowledge and attitudes become cognitively most accessible, how people evaluate various aspects of the situation, and what alternatives are being considered. If the wording of a message corresponds to the goals recipients pursue, the message is likely to be more effective (Reber et al., 1998) and more motivating (Spiegel et al., 2004) compared to messages that do not match with recipients' goals. According to Lindenberg (2006), three different master frames can be identified that represent different core motivations: a normative frame (with the goal 'to act appropriately'), a gain frame (with the goal 'to increase one's resources'), and a hedonic frame (with the goal 'to feel better'). In general, multiple goals are active at any given time, which may (or may not) be compatible, and the strength of the focal goal may be influenced by other goals that are in the background. As mentioned above, both tax payment and charitable giving are social dilemmas, as they involve a tension between what is best for the individual and what is best for the society as a whole. In both contexts, a gain goal frame and a hedonic goal frame would imply acting in line with individual interests (e.g., being non-compliant and self-oriented), whereas a normative goal frame would imply acting in a prosocial way (i.e., paying taxes and giving money to charities). The normative goal frame, however, is the most precarious one and it 
is likely to be displaced by one of the other two overarching goals, unless it gets extra support. Thus, in the contexts of both tax payments and donations, interventions could be aimed at rendering gain and hedonic background goals less incompatible or more compatible with normative goals (Lindenberg and Steg, 2007).

The present study aims to frame information so that the two conflicting background goals in tax payment and charitable giving domains (i.e., gain goal frame and hedonic goal frame) will be more compatible with the overarching normative goal and provide extra support. Since a gain goal frame is very sensitive to changes in personal resources, the criterion for its realization is an improvement of (or prevention of decrease in) one's resources or efficiency of resources. In the context of both tax behaviour and charitable giving, it could be related to a gain in term of services. In a hedonic goal frame, the occurrence of prosocial behaviour is strictly related to how one feels and reacts to particular situations, such as avoiding effort, avoiding negative thoughts and events, avoiding direct uncertainty, seeking direct pleasure, seeking direct improvement in self-esteem, seeking excitement, etc. Both paying taxes and making donations are decisions that can affect people's feelings and mood (e.g., avoiding guilt or looking for 'warm glow' feelings, Andreoni, 1990).

In the field of tax behaviour there is some evidence that seems to support the effectiveness of the gain goal frame and its supportive role to the normative goal frame, by stressing that taxation is necessary to fund public services that benefit everyone, as well as specific items from which one gains in particular (Chirico et al., 2016; Doerrenberg and Peichl, 2017; Hallsworth et al., 2017). Although none of these studies explicitly refer to the goal framing theory, they all suggest that providing information on public utilities one can get in return is more effective than simply focusing on the social norm. In addition, a recent study suggests that when people financially provide for the common good (e.g., when paying taxes) 'personal gain' can be seen as an antecedent as well as making public utilities and services accessible to anyone (Castiglioni et al., 2019). The hedonic frame, instead, is relatively unexplored.

Concerning charitable giving there is mixed evidence about the effectiveness of using a gain goal frame vs. a hedonic goal frame as an extra support for the normative goal frame, which seems also to derive from different motivations behind donations. Generally, a distinction has been made between emotional appeals (i.e., focusing on emotions) and rational appeals (i.e., focusing on practical and utilitarian values and/or charities' effectiveness). Messages appealing to the emotional return of monetary donations seem to be more effective than messages appealing to charities' effectiveness (Banks et al., 1995; Cao, 2016; Chang and Lee, 2009; Dunn et al., 2008; Homer and Yoon, 1992; Smith and Berger, 1996). There is some evidence, however, suggesting that rational messages can have a greater influence on some people, such as individualists (Kim, 2016) and altruistic donors, who seem to respond more positively to information about the effectiveness of their donation (Karlan and Wood, 2017).

Although previous evidence (Castiglioni et al., 2018) suggests that a material return is more important when paying taxes whereas an emotional return is more important when making donations, it cannot be excluded that a gain goal frame could also have a positive effect on charitable giving and, vice versa, a hedonic goal frame on tax compliance, at least if compared to a situation where no returns are explicitly made salient (no frame condition). Thus, we conducted an experimental study to test the following hypotheses:
Hypothesis 1a: Making background goal frames (i.e., gain goal frame and hedonic goal frame) more compatible with the overarching normative frame will increase the intention to pay taxes, when compared to a 'no frame' condition.

Hypothesis 1b: A supporting gain goal frame will have a greater impact on intention to pay taxes than a supporting hedonic goal frame.

Hypothesis 2a: Making background goal frames (i.e., gain goal frame and hedonic goal frame) more compatible with the overarching normative frame will increase the intention to make donations, when compared to a 'no frame' condition.

Hypothesis 2b: A supporting hedonic goal frame will have a greater impact on the intention to donate money than a supporting gain goal frame.

Intrinsic vs. extrinsic motivation. It must be acknowledged that different motives-intrinsic or extrinsic in nature-can influence intention to pay taxes (Eichenberger and Frey, 2002; Gangl et al., 2015; Kirchler et al., 2008) and to make monetary donations (Andreoni and Petrie, 2004; Batson and Shaw, 1991; Meier, 2007). It is plausible to believe that frames work differently according to one's proclivity to be intrinsically or extrinsically compliant with the fiscal system (e.g., voluntary vs. enforced tax compliance) or to give to charities (e.g., altruistic vs. selfish motives). In the context of taxation, when an intrinsic motivation prevails, individuals are less likely to consider the chances of evading and more likely to contribute their share out of a sense of moral obligation. In the context of charitable giving, the intrinsic motivation connects to the value of giving per se, represented by a private preference for others' well-being (i.e., pure altruism). When an extrinsic motivation prevails, on the other hand, people are mostly concerned about avoiding a sanction (i.e., a penalty, a fee, or social disapproval) or getting a reward (either material or nonmaterial, e.g., a gift or reputational benefits).

Since intrinsically motivated people should be more willing to pay taxes or making donations, we believe that supporting goal frames would be especially relevant in increasing willingness to pay/give money when an extrinsic motivation prevails. Thus, the following hypotheses are also formulated:

Hypothesis 3: The effect of goal frames on intended tax compliance is stronger [weaker] when an extrinsic [intrinsic] motivation to pay taxes prevails.

Hypothesis 4: The effect of goal frames on donation intention is stronger [weaker] when an extrinsic [intrinsic] motivation to make monetary donations prevails.

\section{Method}

Design. The study used a 2 (context of contribution: paying taxes vs. making donations) ${ }^{\times} 3$ (framing condition: control vs. gain frame vs. hedonic frame) mixed-factorial design. Framing condition was a between-subjects factor, whereas context of contribution was a within-subjects factor. Blocks related to the within-subjects factor (i.e., paying taxes, ' $\mathrm{T}$ '; and making donations, 'D') were counterbalanced within each framing condition, for a total of six different conditions (see also Table 1). Participants were randomly assigned to one of the six conditions.

Table 1 Number of observations for each condition

\begin{tabular}{lllll} 
& Control & Gain frame & Hedonic frame & Total \\
\hline$T \rightarrow D$ & 70 & 72 & 72 & 214 \\
$\mathrm{D} \rightarrow \mathrm{T}$ & 77 & 76 & 68 & 221 \\
Total & 147 & 148 & 140 & 435 \\
\hline
\end{tabular}




\begin{tabular}{|c|c|c|c|c|}
\hline & Control & Gain frame & $\begin{array}{l}\text { Hedonic } \\
\text { frame }\end{array}$ & Total \\
\hline Female (\%) & 57.8 & 62.2 & 64.3 & 61.4 \\
\hline Graduate (\%) & 70.7 & 73.6 & 68.3 & 71.0 \\
\hline North (\%) & 55.1 & 54.1 & 52.1 & 53.8 \\
\hline Taxpayer (\%) & 68.0 & 72.3 & 62.9 & 67.8 \\
\hline $\begin{array}{l}\text { Income over } \\
20,000(\%)\end{array}$ & 56.1 & 46.5 & 47.5 & 50.0 \\
\hline Donor (\%) & 60.0 & 59.4 & 63.3 & 60.8 \\
\hline Mean age (SD) & $33.7(12.0)$ & 34.5 (12.9) & $34.1(12.5)$ & $34.1(12.5)$ \\
\hline Observations $(N)$ & 147 & 148 & 140 & 435 \\
\hline
\end{tabular}

Participants. A total of 435 Italians participated in the study (see Table 2). They ranged in age from 18 years to 65 years $(M=34.1$ years, $\mathrm{SD}=12.5)$. Overall, 61.4 percent were female, and the sample varied in terms of both region (3.0\% Northeast, $50.8 \%$ Northwest, $4.8 \%$ Central, and $41.4 \%$ Southern), education $(2.3 \%$ Primary school, 26.7\% Secondary school, 26.3\% Bachelor's degree, and $44.7 \%$ Master's degree or higher), and employment status $(49.9 \%$ employees, $17.9 \%$ self-employed/entrepreneurs, $32.2 \%$ students). Regarding annual income, $37.0 \%$ declared a personal gross annual income of less than $€ 10,000,13.0 \%$ between $€ 10,000$ and $€ 19,999,22.8 \%$ between $€ 20,000$ and $€ 29,999$, and $27.2 \%$ at least $€ 30,000{ }^{1}$ Finally, $60.8 \%$ said that they had donated money to charities in the past 12 months.

Using a sample of Italian participants is relevant for the topic, given Italy's fragile public finances situation, long-term economic stagnation, and the effects of the most recent Global Financial Crisis (for the impact of the crisis on spending/saving decisions in the Italian context, see Lozza et al., 2016). According to Eurostat, ${ }^{2}$ in 2017 the Italian government debt equaled 134.7\% of the country's economic output. After Greece (176.2\%), Italy has the second highest ratio of government debt to GDP in the European Union, where the average for 28 countries is $84.1 \%$. As for charitable giving, Italy ranked 54th out of 139 countries in 2017, between Uganda (53rd) and Slovakia (55th), with only $30 \%$ of the population donating money ${ }^{3}$ (CAF World Giving Index, 2017).

Procedure. An online questionnaire was created through the online survey platform Qualtrics. The questionnaire automatically randomly assigned participants to different conditions. An electronic consent form preceded the questionnaire and contained an adequate disclosure regarding the purpose of the study and researcher contact details. Moreover, participants were promised anonymity and were given the option of withdrawing at any time. No incentives were offered for participation.

Framing manipulation. This section will illustrate how the framing manipulation was realized by mean of a funnel-shaped structure (see also Appendix A).

The supporting gain goal frame condition aimed to focus on what one can expect in return from paying taxes and making donations. First, a general question was asked to evoke a specific mindset as well as to check to what extent participants believed there could be a return from paying taxes and making donations before introducing any other manipulation. Next, a brief text was presented, listing some services that people might expect in return when paying taxes or making donations. Finally, a second question was presented, asking participants to indicate three priority areas they believe would require more funding among those listed.

The supporting hedonic goal frame condition aimed to favour a mindset that was oriented to focus on the feelings one can expect as a result of paying taxes or making donations. First, a general question was asked to assess whether or not participants believed one can feel better after paying taxes/making donations. Then, a brief text underlying different sources/motives for personal fulfillment was presented. Finally, a second question was presented, asking participants to indicate the three main reasons among those listed for one to be fulfilled after paying taxes/making donations.

No previous questions/texts were presented to participants in the control group.

Measures. For each condition, intended tax compliance (single item, 'All things considered, how willing are you to pay your taxes?'; scale 1-9) and intention to donate (single item, 'All things considered, how willing are you to make monetary donations?'; scale 1-9) were measured as dependent variables.

In the context of tax payment, scales from the TAX-I inventory (Kirchler and Wahl, 2010) were used to assess voluntary tax compliance (intrinsic motivation; e.g., 'When I pay my taxes as required by the regulation, I do so because I like to contribute to everyone's good') and enforced tax compliance (extrinsic motivation; e.g., 'When I pay my taxes as required by the regulation, I do so because a great many tax audits are carried out'). The Italian validation of the scale was adopted (Berti et al., 2013). Both scales were composed of five items and showed a very good reliability, with a Cronbach's a equal to .86 and .91 , respectively. The correlation between the two scores was significant and negative, $r=-.30, p<.001$.

In the context of charitable giving, two of six factors from the Prosocial Tendencies Measure (PTM, Carlo and Randall, 2002) were used to assesses two types of prosocial behaviours: 'Altruism' (intrinsic motivation, five items; e.g., 'I think that one of the best things about helping others is that it makes me look good (reverse coded)') and 'Public' (extrinsic motivation, four items; e.g., 'I can help others best when people are watching me'). Both dimensions showed a good reliability, with a Cronbach's a equal to .70 and .86 , respectively. The correlation between the two scores was significant and negative, $r=-.65, p<.001$.

Data analysis. The empirical strategy was to examine the effect of framings on intended tax compliance and donation intention. Moderation analyses were performed to detect any interaction between framing condition and intrinsic/extrinsic motivation. Before that, some preliminary analyses were performed in order to check for sequence effects, groups homogeneity, and normal distribution.

Sequence effects. The two contexts (paying taxes, 'T', and making donations, 'D') were presented in separate blocks, and the order of presentation was counterbalanced across the participants $(\mathrm{T} \rightarrow \mathrm{D}$ vs. $\mathrm{D} \rightarrow \mathrm{T})$. To check for possible sequence effects, independent-samples t-tests were conducted to compare the dependent variables (intention to pay taxes and intention to make donations) in $\mathrm{T} \rightarrow \mathrm{D}$ and $\mathrm{D} \rightarrow \mathrm{T}$ sequences. No significant effects were found on intention to pay taxes (control, $t[145]=0.25, p=$ n.s.; gain frame, $t[146]=0.75, p=$ n.s.; hedonic frame, $t[138]$ $=.12, p=$ n.s.), or on intention to make donations (control, $t$ $[145]=1.67, p=$ n.s.; gain frame, $t[146]=1.74, p=$ n.s.; hedonic frame, $t[138]=1.73, p=$ n.s.). Given the lack of sequence effects, data were collapsed in three groups for statistical analysis (i.e., control group, gain frame, and hedonic frame). 


\begin{tabular}{|llll|}
\hline $\begin{array}{l}\text { Table } 3 \text { Skewedness and kurtosis for intended tax } \\
\text { compliance and donation intention }\end{array}$ & \\
& & Skewedness & Kurtosis \\
\hline Intended tax compliance & Control group & -.664 & -.628 \\
& Gain frame & -.348 & -.754 \\
Donation intention & Hedonic frame & -.737 & -.325 \\
& Control group & -.407 & -.728 \\
& Gain frame & -.590 & -.615 \\
& Hedonic frame & -.540 & -.152 \\
\hline
\end{tabular}

Group homogeneity. Chi-square tests were conducted to test the homogeneity of three different groups for socio-demographic characteristics and a one-way ANOVA was performed to compare age. No significant differences were found between the control condition, the gain frame condition, and the hedonic frame condition, thus suggesting that random assignment was valid ex post. In addition, we compared scores for intrinsic/ extrinsic motivation for each group to assess whether any interference with the framing manipulation (i.e., priming effect) occurred. Levene's test was non-significant for all four intrinsic/ extrinsic motivation variables, thus suggesting group homogeneity of variances. Analysis of variance also resulted nonsignificant for both Enforced tax compliance $(F[2,292]=.291$, $p=$ n.s. $)$, Voluntary tax compliance $(F[2,292]=1.785, p=$ n.s. $)$, Public $(F[2,292]=1.446, p=$ n.s. $)$, and Altruism $(F[2,292]$ $=.096, p=$ n.s.). Thus, we assumed that no interference between framing conditions and motivational traits occurred.

Diagnostic for normality. Finally, we tested normality of distribution for all three groups in relation to the two dependent variables: intended tax compliance and donation intention. Table 3 shows skewedness and kurtosis for each subgroup. All values appear to be in the acceptable range for normal distribution. Q-Q plots are also reported in Appendix B.

\section{Results}

Before testing the research hypotheses, some exploratory analyses were performed. These revealed an interaction effect between framing condition and employment on intention to pay taxes (framing condition $\times$ employment, $F(4,426)=2.535, p<.05$, $\eta^{2}=.03$ ), with students differing from taxpayers (i.e., employees, self-employed individuals, and entrepreneurs). This difference can be attributed to the fact that students have no direct or regular experience with tax payment. Thus, analysis of a subsample of taxpayers will be presented first $(67.8 \%$ of total sample, $n=295$ ). Subsequently, results on taxpayers will be compared with the results from the sub-sample of students.

Framing effects. A two-way mixed ANOVA was performed on the sub-sample of taxpayers to determine the effects of the framing condition (between subjects: control vs. gain frame vs. hedonic frame) and context of contribution (paying taxes vs. making donations) on the intention to make a financial contribution. Levene's test was significant for both intended tax compliance $(F(2$, $292)=6.790, p<.01)$ and donation intention $(F(2,292)=4.058, p$ $<.05)$, thus violating the assumption of homogeneity of variances. However, analysis of variance is reasonably robust to violations of this assumption provided that the size of groups is similar (Box, 1953; Lix et al., 1996), as is the case for this study.

A significant interaction effect between framing condition and context of contribution was found, $F(2,292)=6.499, p<.01$, $\eta^{2}=.04$.

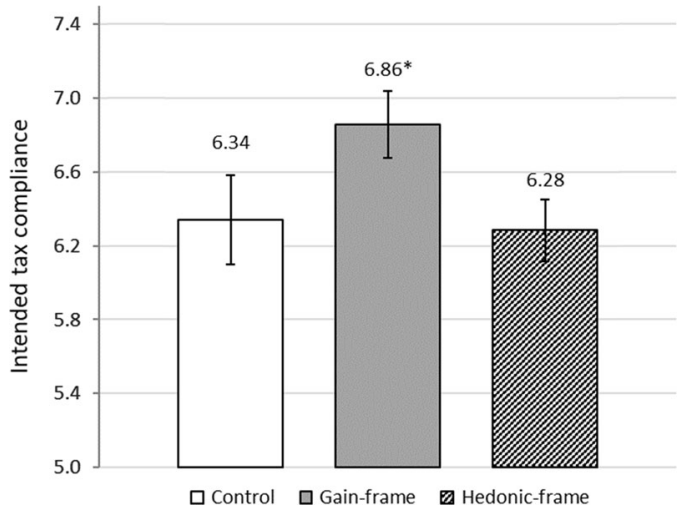

Fig. 1 Intention to pay taxes as a function of framing conditions. The gain frame condition is significantly different from both control group and hedonic frame condition at the .05 level

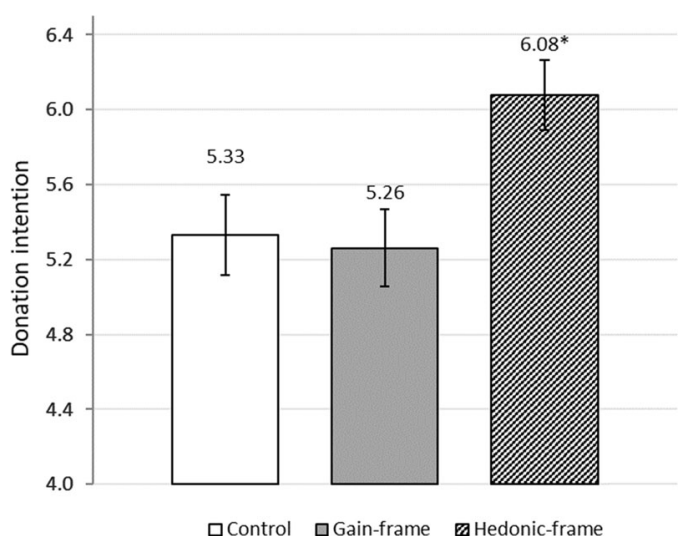

Fig. 2 Donation intention as a function of framing conditions. The hedonic frame condition is significantly different from both control group and gain frame condition at the .05 level

Post hoc tests revealed that participants in the gain frame condition reported a higher intention to pay taxes $(M=6.86)$ compared to participants in either the control condition $(M=6.34)$ or the hedonic frame condition $(M=6.28)$. Whereas the donation context showed an opposite pattern, with participants in the hedonic frame condition $(M=6.08)$ reporting a higher intention than either participants in the control condition $(M=5.33)$ or the gain frame condition $(M=5.26)$. It should be noted that, in the tax context, the hedonic frame group was not significantly different from the control group (see Fig. 1). Similarly, in the donation context, the gain frame group did not significantly differ from the control group (see Fig. 2). Therefore, Hypothesis 1a and Hypothesis 2a were only partially supported, since only one of two different supporting goal frames (the gain goal frame for intended tax compliance and the hedonic goal frame for donation intention, respectively) is effective in increasing the intention to make a financial contribution if compared to the condition with no frame. Hypothesis $1 \mathrm{~b}$ and Hypothesis $2 \mathrm{~b}$, however, were fully supported; a supporting gain goal frame had a greater impact on intention to pay taxes than a supporting hedonic goal frame, and a supporting hedonic goal frame had a greater impact on intention to make donations than a supporting gain goal frame (Hypothesis 2b).

This result was also in line with the different beliefs that participants reported regarding taxes and donations. Overall, 


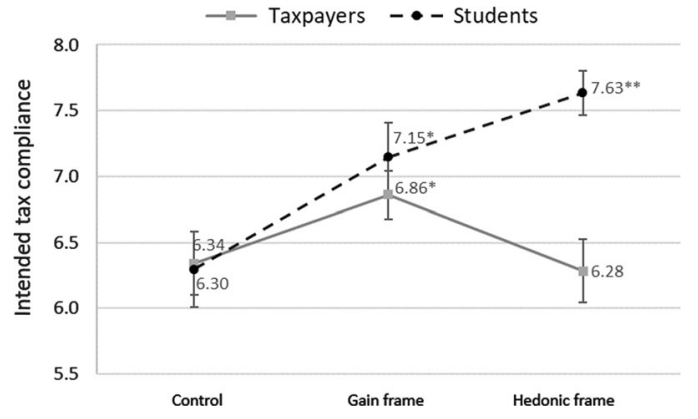

Fig. 3 Interaction effect between employment and framing condition in tax payment context. For students, both gain frame and hedonic frame conditions are significantly different from the control group at the .05 and .001 level, respectively. For taxpayers, only the gain frame is significantly different from both the control group and hedonic frame at the .05 level

participants believed that paying taxes could aid in the development of the welfare system of a country $(M=6.51$, $\mathrm{SD}=2.18)$ to a greater extent than donations could $(M=5.73$, $\mathrm{SD}=2.08), \quad t(246)=4.631, \quad p<.001$. Whereas participants reported to experience more feelings of fulfillment and personal gratification when making donations $(M=6.49, \mathrm{SD}=1.94)$ rather than when paying taxes $(M=4.79, \mathrm{SD}=2.34)$, $t(242)=9.968, p<.001$.

Taxpayers vs. students. As mentioned above, an interaction effect between employment and framing condition was found. This evidence lead to an exploratory analysis of the difference between taxpayers and students. A comparison of sub-sample of students $(n=140)$ with the sub-sample of taxpayers in the context of tax payment, indicated that students did not differ significantly from taxpayers either in the control condition $(t(145)=0.105, p=$ n.s. $)$ or in the gain frame condition $(t(146)=0.859, p=\mathrm{n} . \mathrm{s})$. In contrast, they did significantly differ in the hedonic frame condition $(t(138)=4.001, p<.001)$, with students $(M=7.63, \mathrm{SD}=1.20)$ being more affected by the emotional return than taxpayers $(M=6.28, \mathrm{SD}=2.25)$. No differences between taxpayers and students were found in the context of charitable giving. Figure 3 shows the interaction effect between employment and framing condition. Whereas for taxpayers the gain frame was the only condition that significantly differed from the others, post-hoc tests revealed that, for students, not only was the gain frame condition significantly different from that of the control group $(p<.05)$, but also the hedonic frame condition was statistically different $(p<.001)$. No statistically significant differences were observed between the gain frame and the hedonic frame. In other words, both goal frames were effective in increasing students' intention to comply with the tax system.

Intrinsic vs. extrinsic motivation: Interaction effects. Hierarchical regressions were performed separately on intended tax compliance and donation intention to test interaction effects between framing conditions and intrinsic/extrinsic motivation to comply/donate. All continuous variables were mean-centered, and the categorical variable (i.e., framing conditions) was recoded into two dummy variables. Giving the observed differences between taxpayers and students, only taxpayers were included for the analysis on intended tax compliance.

Intended tax compliance. Enforced tax compliance and framing conditions were entered in the first step of a hierarchical regression, and the resulting model explained $8 \%$ of the variance

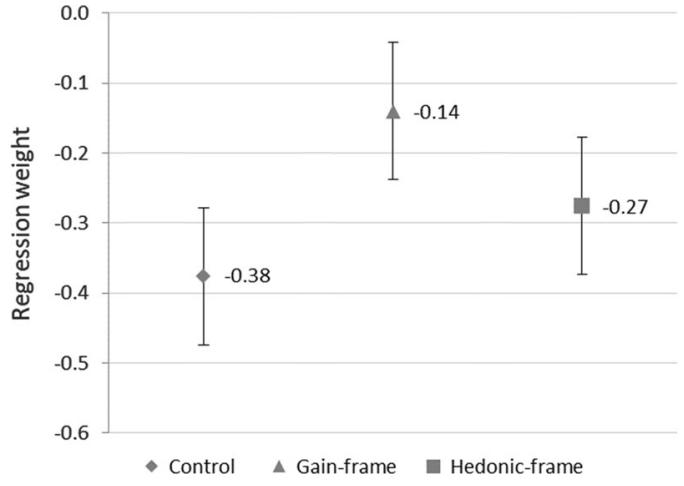

Fig. 4 Regression weights of enforced tax compliance (i.e., extrinsic motivation) on intended tax compliance in different framing conditions

in intended tax compliance, $F(3,269)=8.057, p<.001$. Enforced tax compliance $(\beta=-.26, t=4.426, p<.001)$ was negatively related to intention to comply, indicating that tax compliance is lower when people score high on enforced tax compliance (extrinsic motivation). Next, the two-way interactions between framing conditions and enforced tax compliance were entered $\left(R_{c h}^{2}=.01\right), F(5,267)=24.195, p<.001$. Results indicate that only the Enforced tax compliance $x$ gain frame interaction has a relationship with tax compliance $(\beta=.15, t=1.747, p<.10)$, with an effect size of $f^{2}=.01{ }^{4}$ Interestingly, this relationshipalthough only significant at $p<.10$-was positive. Inspection of the regression weights suggests that, although the main effect of enforced tax compliance on intended tax compliance is negative, a supporting gain goal frame can mitigate such negative effect, as suggested by Hypothesis 3 (see Fig. 4 and Appendix C for full regression results).

Next, voluntary tax compliance and framing conditions were entered in the first step of a hierarchical regression, and the resulting model explained $28 \%$ of the variance in intention to pay taxes, $F(3,269)=35.529, p<.001$. Voluntary tax compliance $(\beta=.52, t=10.036, p<.001)$ was positively related to intended tax compliance. Then, the two-way interactions between framing conditions and voluntary tax compliance were entered, but no significant interactions were found.

Donation intention. A hierarchical regression was performed on donation intention by first entering 'Public' dimension of prosocial tendencies (i.e., extrinsic motivation) and framing conditions. The resulting model only explained $5 \%$ of the variance in intention to make donations, $F(3,385)=6.118, p<.001$. 'Public' $(\beta=-.10, t=3.284, p<.01)$ was negatively related to donation intention. Next, the two-way interactions between framing conditions and Public were entered, but no significant interactions were found, thus not supporting Hypothesis 4.

Moving on to the intrinsic motivation in charitable giving context, in the first step of the hierarchical regression it was found that Altruism $(\beta=.03, t=0.685, p=$ n.s. $)$ had no significant main effect on donation intention. Next, the two-way interactions between framing conditions and Altruism were entered $\left(R_{\mathrm{ch}}^{2}\right.$ $=.01), F(5,383)=3.770, p<.01$. Results indicate that only the Altruism $\times$ hedonic frame interaction has a negative relationship with donation intention $(\beta=-.13, t=1.938, p=.05)$, with an effect size of $f^{2}=.01$. Inspection of the regression weights suggests that donation intention is lower when people score high on altruism and are paired with a hedonic frame, at least if compared with control condition and a gain frame. This result suggests that, although altruism seems to have no main effect on intention to make donations, a supporting hedonic goal frame in 


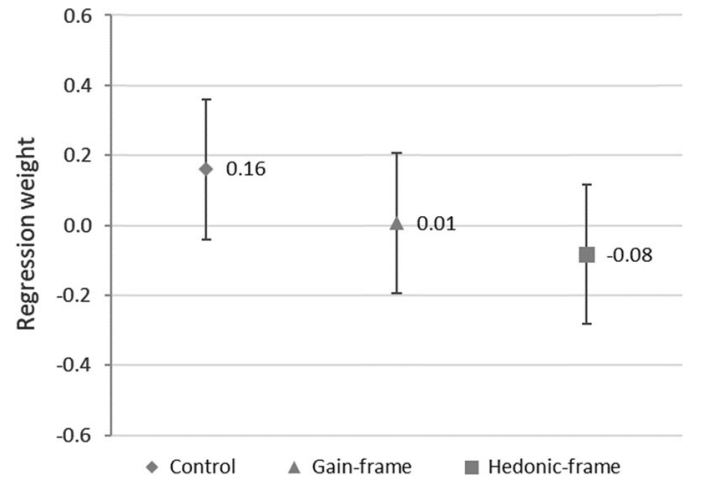

Fig. 5 Regression weights of Altruism (i.e., intrinsic motivation) on donation intention in different framing conditions

presence of high levels of altruism (i.e., intrinsic motivation) can be counter-productive on donation intention (see Fig. 5).

\section{Discussion}

Based on the goal-framing theory, this study aimed at testing whether making two background goal frames (i.e., gain goal frame and hedonic goal frame) more salient and compatible with the overarching normative goal frame could increase the intention to pay taxes and make charitable donations. Results showed that a supporting gain frame was only effective in increasing intended tax compliance, whereas a supporting hedonic frame was only effective in increasing donation intention.

In the context of taxation, not only goal frames were not equally effective to promote tax compliance-since a supporting gain goal frame was more effective than a supporting hedonic goal frame-but a hedonic frame was not different from no frame at all (Hypothesis 1a not fully supported; Hypothesis $1 \mathrm{~b}$ fully supported). Interestingly, such results only applied to a subsample of taxpayers (i.e., employees, self-employed people, and entrepreneurs). Students were found to differ from taxpayers, as for students the hedonic frame was effective in increasing intended tax compliance as well (only for students Hypothesis 1a was fully supported). Presumably, students' lack of tax experience can explain this difference. In particular, students may process tax-related information differently from taxpayers, being tax payment an atypical or unusual situation for them (see also Affective Infusion Model; Forgas, 1995).

This result leads to two different considerations, a theoretical and a pragmatic one. At the theoretical level, it appears that to some extent-at least at a formal level and before real tax experience is gained-paying taxes and making donations can be seen as two sides of the same coin. However, things seem to change, especially at an affective level, with the acquisition of real tax experience. At a pragmatic level, the current findings suggest that-at least in the field of tax compliance research-caution is needed when studies are solely conducted on a population of students, as results may not apply to taxpayers. Despite some studies suggest that the experimental tax behaviour of students is often-although not always-similar to the experimental behaviour of other subjects (see Alm et al., 2015) it has been also found that in tax compliance experiments students are more responsive to policy levers than non-students are (Choo et al., 2016) and respond differently to audit probability (Marriott et al., 2013).

Moving to the donation context, it was found that a supporting hedonic goal frame was more effective than a supporting gain goal frame, and a supporting gain goal frame was not different from no frame at all (Hypothesis 2a not fully supported; Hypothesis $2 \mathrm{~b}$ fully supported). No differences between students and taxpayers were found, which can be explained by that both students and taxpayers may have similar levels of familiarity and experience with charitable giving. The current study suggests that focusing on feelings is effective in promoting donation intention. This result is in line with those studies suggesting that in the context of charitable giving a soft-sell approach, which typically appeals to the audience's emotions, is more effective than a hardsell approach, which typically focuses on claims about practical, functional, or utilitarian values (Okazaki et al., 2010). This result is also line with other evidence from the literature arguing that sometimes donors do not primarily care about results and fundraising efficiency (Berman and Davidson, 2003; Charles and Kim, 2016; Gordon and Khumawala, 1999). In other words, the effort-rather than the actual outcome-seems to be more valuable, leading to the idea that 'it's the thought that counts'. Briers et al. (2007) suggest that because donor are already 'buying' something immaterial (e.g., a warm glow feelings), perhaps it is not necessary to offer them an additional gain. However, in the current study, the gain frame was not presented as a personal gift or item, but rather as an overall increase in services and general welfare from which one could also personally benefit. Another possible explanation of such result comes from the distinction between altruism donors (who enjoy seeing the wellbeing of others increase), and warm-glow donors (who gain pleasure from the act of giving itself). Further considerations about this distinction will be provided below, when elaborating on the differences between intrinsic and extrinsic motivation.

A second aim of this study was to assess whether frames worked differently in the presence of an intrinsic/extrinsic motivation to pay taxes/make donations. In the tax context, it was found that tax compliance was lower when taxpayers scored high on enforced tax compliance (extrinsic motivation). In contrast, tax compliance was higher when taxpayers scored high on voluntary tax compliance (intrinsic motivation). Both results are in line with the 'slippery slope' framework and other empirical results, where enforced compliance has been found to lead to increased tax evasion whereas voluntary compliance has been found to lead to reduced tax evasion (Kastlunger et al., 2013; Wahl et al., 2010). Frames were expected to have stronger effect on intended tax compliance in presence of high levels of extrinsic motivation to pay taxes (see Hypothesis 3). Accordingly, a significant interaction effect was found between the gain frame and extrinsic motivation, thus suggesting that focusing on what one can get in return is especially effective when taxpayers are extrinsically motivated to pay taxes. In other words, although enforced compliance has a negative effect on intention to pay taxes, a gain frame can mitigate such negative effect. No interaction effect was found between frames and intrinsic motivation to comply, as high levels of voluntary tax compliance are effective by themselves at increasing intended tax compliance. This result is especially relevant for those countries with low trust and high power, where enforced tax compliance and an antagonistic fiscal climate prevail, including Italy (see Batrancea et al., 2016; Lozza and Castiglioni, 2018). In such countries, where the high level of tax evasion can also be explained-among other factors - by the tense relationships between taxpayers and tax authorities, and people pay taxes out of fear rather than out of a sense of civic duty, framing tax-related information in terms of gains in public services can nudge people towards higher levels of tax compliance.

In the charitable giving context, no interaction effect was found between frames and extrinsic motivation (see Hypothesis 4). This may be related to a measurement issue. The 'Public' dimension of the PTM scale (Prosocial Tendencies Measure, Carlo and Randall, 2002) does not specifically focus on charitable giving but rather focuses on a broader range of prosocial behaviour (e.g., helping others or voluntary work). The extrinsic motivation to be 
prosocial in public, which is mostly reputational as someone else is watching, may refer more to voluntary work and general helping than to giving money to charities. In the context of monetary donations, extrinsic motivations may mostly refer to the so-called 'fringe benefits' (Olson, 1965) or when an item is offered in exchange of a donation. Interestingly, an interaction effect was found between intrinsic motivation (i.e., altruism) and the hedonic frame suggesting that focusing on feelings can work for warm glow donors but can be counter-productive in the case of pure altruist donors. It appears that the hedonic frame (which is the only one that was found to have an effect on donation intention) is less effective in presence of high levels of intrinsic motivation to behave prosocially. It might be that this kind of frame makes the pure altruists aware that there is always some kind of individual return when making a donation, even if it is just at an emotional level. As several experiments have shown, extrinsic motivations can crowd out intrinsic motivations and lead people to behave less prosocially (Chao, 2017; Deci, 1971; Gneezy and Rustichini, 2000; Frey and Jegen, 2001). Donation intention may also decrease because the gesture can no longer be seen as a self-signal of altruism (Bem, 1965; Bénabou and Tirole, 2006). Alternatively, according to the attention-based multiattribute choice models (Bordalo et al., 2012; Krajbich et al., 2012; McGill and Anand, 1989), if the personal return is a particularly salient attribute, this may cause the donor to underweight less salient intrinsic motives such as altruism, potentially leading to lower motivation to donate.

To summarize, it appears that baseline motivation is an important factor that determines how people respond to different frames in the mandatory and/or voluntary provision of common goods (see also Boyer et al., 2016). Interestingly, while in the tax domain high levels of intrinsic motivation had a significant main effect on intended tax compliance and no interaction effects with the frames, in the charitable giving domain intrinsic motivation had no main effect on donation intention but showed a significant and negative interaction with hedonic frame. In both contexts, it can be observed that the use of framing effects in the presence of high levels of intrinsic motivation to make a financial contribution to the common good appears to have no added value, since it has either no effect (as in the case of tax compliance) or a negative relation (as in the case of donation intention).

Some limitations of this study need to be taken into account as well. From a methodological perspective, it should be noted that self-report intentions rather than actual behaviour were used as dependent variables. In psychological literature, positive correlations were found between self-reported and actual tax-paying behaviour (Hite, 1988), and several studies used intention to comply as a proxy for actual tax-paying behaviour (e.g., see Brizi et al., 2015; Kaplanoglou et al., 2016; Kasper et al., 2015; Wahl et al., 2010). Nonetheless, evidence can also be found suggesting that taxpayers' stated intentions to comply may not correspond to subsequent observed behaviour (Gemmell and Ratto, 2018). As for charitable giving, intention to donate is the most consistent predictor of charitable giving behaviour (e.g., Greenslade and White, 2005; Smith and McSweeney, 2007; Warburton and Terry, 2000) and can act as a suitable proxy measure for behaviour when actual behaviour is not measured (Chacòn et al., 2007). Nonetheless, future research should adopt both laboratory and field experiments to verify whether similar frame effects can be found on observable variables too. Furthermore, research should examine whether the nature of charitable contexts would moderate framing effects. While the present study considered donation intention in a general sense, both the nature of charitable issues (e.g., underprivileged groups, environmental protection, scientific research, art promotion, etc.) and the location (e.g., local, national, international aid) may strengthen or weaken the framing effectiveness. Goal frames can be further analyzed too. For example, it would be interesting to compare the effects of a positive hedonic goal frame (i.e., seeking positive emotions) and a negative hedonic goal frame (i.e., avoiding negative emotions). Finally, it should also be noted that our study was conducted in Italy; a country with a very peculiar socio-economic context (high level of shadow economy, huge public debt, political instability, low level of donations) and where tax evasion is not perceived as a serious crime (Castiglioni et al., 2014; Cullis et al., 2015). It would be interesting to compare such results with results obtained in other countries, especially those where tax compliance is higher and donations to charities are more frequent and consistent.

A final consideration concerns the effect size of the impact of frames on contribution intention (4\%). This relative small effect size suggests that the financial provision for the common good is a complex matter, and many other variables can play a role in explaining a great deal of additional variance. Nonetheless, if we multiply this small effect by the amount of taxes paid by almost 41 million Italian taxpayers and the potential donated money by over 50 million Italians over 18 years old, ${ }^{5}$ the impact on Italian public finance would be quite relevant. Thus, despite the small effect, it is worthwhile to further explore this area of research as results can have significant practical implications.

\section{Conclusions}

In conclusion, it appears that, despite being two ways to financially provide for the common good, at psychological and affective level taxes and donations are not two sides of the same coin. In this study, different supporting goal frames proved to be effective in strengthening the overarching normative goal frame to act appropriately. Specifically, a supporting gain goal frame was effective on intended tax compliance, whereas a supporting hedonic goal frame was effective on donation intention.

Nonetheless, it should be taken into account that frames might work differently according to the prevailing motivation behind such contributions. Among intrinsically motivated individuals, the gain goal frame seems to have no effect on intended tax compliance and the hedonic goal frame can actually decrease intended charitable donations. In the presence of enforced tax compliance (i.e., extrinsic motivation) and low levels of altruism, instead, frames are especially relevant. These findings, besides being valuable at theoretical level and adding to the existing literature, may have real-world implication, especially if integrated with evidence from real-world behaviour. Further evidence, building up on these insights, can help policy-makers, administrators, and NGOs to understand how to develop effective policies and social communication campaigns. Being aware of the effects of different of appeals can help to pursue positive societal outcomes in terms of financially providing for the common good and avoid potential unintended negative consequences (e.g., as in the case of emotional appeals for charity donations).

\section{Data availability}

The dataset generated and analysed during the current study are available from the corresponding author on reasonable request.

Received: 28 November 2018 Accepted: 27 March 2019

Published online: 16 April 2019

\section{Notes}

1 According to the most recent IRPEF estimates, the average Italian income declared to fiscal authorities in 2015 was $€ 20,690$ (http://wwwl.finanze.gov.it/finanze2/ analisi_stat/index.php?tree $=2016$ ). 
2 See: http://ec.europa.eu/eurostat/documents/2995521/8118661/2-20072017-AP-EN pdf/83147478-c193-40e9-8a0a-b76e56a5cebc

3 The average percentage of the population that donates money in Europe stands at $36 \%$, with the United Kingdom (64\%) and the Netherlands (64\%) having the largest proportions of people making donations.

4 According to Aguinis et al. (2005), $f^{2}$ values of $.005, .01$, and .025 can be considered as small, medium, and large effects, respectively.

5 Data retrieved from ISTAT (March 2018): http://demo.istat.it/pop2017/index.html

\section{References}

Aguinis H, Beaty JC, Boik RJ, Pierce CA (2005) Effect size and power in assessing moderating effects of categorical variables using multiple regression: a 30year review. J Appl Psychol 90(1):94-107

Alm J, Bloomquist KM, McKee M (2015) On the external validity of laboratory tax compliance experiments. Econ Inq 53(2):1170-1186

Andreoni J (1990) Impure altruism and donations to public goods: a theory of warm-glow giving. Econ J 100(401):464-477

Andreoni J, Petrie R (2004) Public goods experiments without confidentiality: a glimpse into fund-raising. J Public Econ 88(7):1605-1623

Banks SM, Salovey P, Greener S, Rothman AJ, Moyer A, Beauvais J, Epel E (1995) The effects of message framing on mammography utilization. Health Psychol 14(2):178-184

Batrancea L, Nichita A, Batrancea I, Kirchler E (2016) Tax Compliance Behavior: An Upshot of Trust in and Power of Authorities across Europe and MENA. In: Erdoğdu MM, Christiansen B (Eds.) Handbook of research on public finance in Europe and the MENA region. IGI Global, Hershey, PA, p 248-267

Batson CD, Shaw LL (1991) Evidence for altruism: toward a pluralism of prosocial motives. Psychol Inq 2(2):107-122

Bem DJ (1965) An experimental analysis of self-persuasion. J Exp Soc Psychol $1: 199-218$

Bénabou R, Tirole J (2006) Incentives and prosocial behavior. Am Econ Rev 96 (5):1652-1678

Berman G, Davidson S (2003) Do donors care? Some Australian evidence. Volunt: Int J Volunt Nonprofit Organ 14(4):421-429

Berti C, Kastlunger B, Kirchler E (2013) The slippery slope of the tax behavior: Italian validation of a compliance inventory. G Ital di Psicol 40(2):377-408

Bordalo P, Gennaioli N, Shleifer A (2012) Salience theory of choice under risk. Q J Econ 127(3):1243-1285

Boyer PC, Dwenger N, Rincke J (2016) Do norms on contribution behavior affect intrinsic motivation? Field-experimental evidence from Germany. J Public Econ 144:140-153

Box GE (1953) Non-normality and tests on variances. Biometrika 40(3/4):318-335

Briers B, Pandelaere M, Warlop L (2007) Adding exchange to charity: a reference price explanation. J Econ Psychol 28(1):15-30

Brizi A, Giacomantonio M, Schumpe BM, Mannetti L (2015) Intention to pay taxes or to avoid them: the impact of social value orientation. J Econ Psychol 50:22-31

CAF Charities Aid Foundation (2017) World giving index 2017. https://www.cafonline.org/docs/default-source/about-us-publications/ cafworldgivingindex2017_2167a_web_210917.pdf?sfvrsn=ed1dac40_10. Accessed 15 Jan 2019

Cao X (2016) Framing charitable appeals: the effect of message framing and perceived susceptibility to the negative consequences of inaction on donation intention. Int J Nonprofit Volunt Sect Mark 21(1):3-12

Carlo G, Randall BA (2002) The development of a measure of prosocial behaviors for late adolescents. J Youth Adolesc 31(1):31-44

Castiglioni C, Lozza E, Bonanomi A (2019) The common good provision scale (CGP): A tool for assessing people's orientation towards economic and social sustainability. Sustainability 11(2):370

Castiglioni C, Lozza E, Bosio AC (2018) Lay people representations on the common good and its financial provision. SAGE Open 8 (4):2158244018807247

Castiglioni C, Lozza E, Cullis J, Jones P, Lewis A (2014) Frodare il sistema fiscale è più o meno grave di evadere le tasse? Uno studio esplorativo nella prospettiva della psicologia fiscale. Psicol Soc 9(3):291-308

Chacòn F, Vecina ML, Davila MC (2007) The three-stage model of volunteers' duration of service. Soc Behav Personal: Int J 35(5):627-642

Chang CT, Lee YK (2009) Framing charity advertising: Influences of message framing, image valence, and temporal framing on a charitable appeal. J Appl Soc Psychol 39(12):2910-2935

Chao M (2017) Demotivating incentives and motivation crowding out in charitable giving Proc Natl Acad Sci 114(28):201616921

Charles C, Kim M (2016) Do donors care about results? An analysis of nonprofit arts and cultural organizations. Public Perform Manag Rev 39(4):864-884

Chirico M, Inman RP, Loeffler C, MacDonald J, Sieg H (2016) An experimental evaluation of notification strategies to increase property tax compliance: freeriding in the city of brotherly love. Tax Policy Econ 30(1):129-161
Choo CL, Fonseca MA, Myles GD (2016) Do students behave like real taxpayers in the lab? Evidence from a real effort tax compliance experiment. J Econ Behav Organ 124:102-114

Cullis J, Jones P, Lewis A, Castiglioni C, Lozza E (2015) Do poachers make harsh gamekeepers? Attitudes to tax evasion and to benefit fraud. J Behav Exp Econ 58:124-131

Dawes RM (1980) Social dilemmas. Annu Rev Psychol 31:169-193

Deci EL (1971) Effects of externally mediated rewards on intrinsic motivation. J Personal Soc Psychol 18(1):105-115

Doerrenberg P, Peichl A (2017) Tax morale and the role of social norms and reciprocity: evidence from a randomized survey experiment. ZEW Discussion Papers No. 17-045.

Dunn EW, Aknin LB, Norton MI (2008) Spending money on others promotes happiness. Science 319(5870):1687-1688

Dwenger N, Kleven H, Rasul I, Rincke J (2016) Extrinsic and intrinsic motivations for tax compliance: evidence from a field experiment in Germany. Am Econ J Econ Policy 8(3):203-232

Eichenberger R, Frey BS (2002) Democratic governance for a globalized world. Kyklos 55(2):265-287

Elliott CS, Hayward DM, Canon S (1998) Institutional framing: some experimental evidence. J Econ Behav Organ 35(4):455-464

Forgas JP (1995) Mood and judgment: The affect infusion model (AIM). Psychol Bull 117(1):39-66

Frey BS, Jegen R (2001) Motivation crowding theory. J Econ Surv 15(5):589-611

Gangl K, Hofmann E, Kirchler E (2015) Tax authorities' interaction with taxpayers a conception of compliance in social dilemmas by power and trust. New Ideas Psychol 37:13-23

Gemmell N, Ratto M (2018) The effects of penalty information on tax compliance: Evidence from a New Zealand field experiment. Natl Tax J 71(3):547-588

Gneezy U, Rustichini A (2000) Pay enough or don't pay at all. Q J Econ 115 (3):791-810

Gordon TP, Khumawala SB (1999) The demand for not-for-profit financial statements: a model of individual giving. J Account Lit 18:31-56

Greenslade JH, White KM (2005) The prediction of above-average participation in volunteerism: a test of the theory of planned behavior and the volunteers functions inventory in older Australian adults. J Soc Psychol 145(2):155-172

Hallsworth M, List JA, Metcalfe RD, Vlaev I (2017) The behavioralist as tax collector: Using natural field experiments to enhance tax compliance. J Public Econ 148:14-31

Hite PA (1988) An examination of the impact of subject selection on hypothetical and self-reported taxpayer noncompliance. J Econ Psychol 9(4):445-466

Homer PM, Yoon S (1992) Message framing and the interrelationships among adbased feelings, affect, and cognition. J Advert 21:19-33

Kahneman D, Tversky A (1979) Prospect theory: an analysis of decision under risk Économ: J Econom Soc 47(2):263-292

Kaplanoglou G, Rapanos VT, Daskalakis N (2016) Tax compliance behaviour during the crisis: the case of Greek SMEs. Eur J Law Econ 42(3):405-444

Karlan D, Wood DH (2017) The effect of effectiveness: donor response to aid effectiveness in a direct mail fundraising experiment. J Behav Exp Econ 66:1-8

Kasper M, Kogler C, Kirchler E (2015) Tax policy and the news: an empirical analysis of taxpayers' perceptions of tax-related media coverage and its impact on tax compliance. J Behav Exp Econ 54:58-63

Kastlunger B, Lozza E, Kirchler E, Schabmann A (2013) Powerful authorities and trusting citizens: the Slippery Slope Framework and tax compliance in Italy. J Econ Psychol 34:36-45

Kim Y (2016) Cultural orientation affects consumer responses to charity advertising. Soc Behav Personal: Int J 44(7):1079-1088

Kirchler E, Hoelzl E, Wahl I (2008) Enforced versus voluntary tax compliance: The 'slippery slope' framework. J Econ Psychol 29(2):210-225

Kirchler E, Wahl I (2010) Tax compliance inventory TAX-I: designing an inventory for surveys of tax compliance. I Econ Psychol 31(3):331-346

Krajbich I, Lu D, Camerer C, Rangel A (2012) The attentional drift-diffusion model extends to simple purchasing decisions. Front Psychol 3:193

Levin IP, Schneider SL, Gaeth GJ (1998) All frames are not created equal: A typology and critical analysis of framing effects. Organ Behav Hum Decis Process 76:149-188

Lindenberg S (2006) Prosocial behavior, solidarity, and framing processes. In: Fetchenhauer D, Flache A, Buunk B, Lindenberg S (Eds.) Solidarity and prosocial behavior. Springer US, Boston, MA, p 23-44

Lindenberg S, Steg L (2007) Normative, gain and hedonic goal frames guiding environmental behavior. J Soc Issues 63(1):117-137

Lix LM, Keselman JC, Keselman HJ (1996) Consequences of assumption violations revisited: a quantitative review of alternatives to the one-way analysis of variance F test. Rev Educ Res 66(4):579-619

Lozza E, Bonanomi A, Castiglioni C, Bosio AC (2016) Consumer sentiment after the global financial crisis. Int J Mark Res 58(5):671-691

Lozza E, Castiglioni C (2018) Tax climate in the national press: a new tool in tax behaviour research. J Soc Political Psychol 6(2):401-419 
Marriott L, Randal J, Holmes K (2013) Tax experiments in the real world. eJ Tax Res 11(2):216-244

McGill AL, Anand P (1989) The effect of vivid attributes on the evaluation of alternatives: the role of differential attention and cognitive elaboration. J Consum Res 16(2):188-196

Meier S (2007) A Survey of economic theories and field evidence on pro-social behavior. In: Frey BS, Stutzer A (Eds.) Economics and psychology: a promising new cross-disciplinary field. MIT Press, Boston, MA, p 51-88

Okazaki S, Mueller B, Taylor CR (2010) Measuring soft-sell versus hard-sell advertising appeals. J Advert 39:5-20

Olson M (1965) The logic of collective action: public goods and the theory of groups. Harvard University Press, Cambridge

Reber R, Winkielman P, Schwarz N (1998) Effects of perceptual fluency on affective judgments. Psychol Sci 9(1):45-48

Selle P (1993) Voluntary organisations and the welfare state: the case of Norway. Volunt Int J Volunt Nonprofit Organ 4(1):1-15

Slavov SN (2014) Public versus private provision of public goods. J Public Econ Theory 16(2):222-258

Smith GE, Berger PD (1996) The impact of direct marketing appeals on charitable marketing effectiveness. J Acad Mark Sci 24:219-231

Smith JR, McSweeney A (2007) Charitable giving: the effectiveness of a revised theory of planned behaviour model in predicting donating intentions and behaviour. J Community Appl Soc Psychol 17(5):363-386

Spiegel S, Grant-Pillow H, Higgins ET (2004) How regulatory fit enhances motivational strength during goal pursuit. Eur J Soc Psychol 34(1):39-54

Sugden R (1984) Reciprocity: The supply of public goods through voluntary contributions. Econ J 94(376):772-787

Sunstein C, Thaler R (2009) Nudge: Improving decisions about health, wealth, and happiness. Penguin Books, New York, NY

Tversky A, Kahneman D (1981) The framing of decisions and the psychology of choice. Science 211:453-458

Wahl I, Kastlunger B, Kirchler E (2010) Trust in authorities and power to enforce tax compliance: an empirical analysis of the 'Slippery Slope Framework'. Law Policy 32(4):383-406
Warburton J, Terry DJ (2000) Volunteer decision making by older people: a test of a revised theory of planned behavior. Basic Appl Soc Psychol 22 (3):245-257

Wheatley JJ, Oshikawa S (1970) The relationship between anxiety and positive and negative advertising appeals. J Mark Res 7(1):85-89

\section{Additional information}

The online version of this article (https://doi.org/10.1057/s41599-019-0247-4) contains supplementary material, which is available to authorized users.

Competing interests: The authors declare no competing interests.

Reprints and permission information is available online at http://www.nature.com/ reprints

Publisher's note: Springer Nature remains neutral with regard to jurisdictional claims in published maps and institutional affiliations.

\section{(c) (i)}

Open Access This article is licensed under a Creative Commons Attribution 4.0 International License, which permits use, sharing, adaptation, distribution and reproduction in any medium or format, as long as you give appropriate credit to the original author(s) and the source, provide a link to the Creative Commons license, and indicate if changes were made. The images or other third party material in this article are included in the article's Creative Commons license, unless indicated otherwise in a credit line to the material. If material is not included in the article's Creative Commons license and your intended use is not permitted by statutory regulation or exceeds the permitted use, you will need to obtain permission directly from the copyright holder. To view a copy of this license, visit http://creativecommons.org/ licenses/by/4.0/.

(C) The Author(s) 2019 